\title{
Large scale features associated with strong frontogenesis in equivalent potential temperature in the South American subtropics east of the Andes
}

\author{
J. M. Arraut $^{1}$ and H. M. J. Barbosa ${ }^{2}$ \\ ${ }^{1}$ Centro de Ciências do Sistema Terrestre, Instituto Nacional de Pesquisa Espaciais, Av. dos Astronautas, \\ 1758, São José dos Campos SP 12227-010, Brazil \\ ${ }^{2}$ Instituto de Física, Universidade de São Paulo, Rua do Matão, 187, São Paulo SP 05508-090, Brazil
}

Received: 26 April 2009 - Revised: 1 July 2009 - Accepted: 8 July 2008 - Published: 13 October 2009

\begin{abstract}
South American subtropics east of the Andes exhibit a region of intense climatological frontogenesis in equivalent potential temperature (EPT) in the December to March season, mostly produced by deformation of the wind field. The goal of this paper is to investigate the large scale features associated with intense and weak frontogenesis by deformation (FGD) in EPT in the region where it attains its climatological maximum. This can be approximately delimited by $32-42^{\circ} \mathrm{S}$ and $66-69^{\circ} \mathrm{W}$, which is small enough as to contain only one synoptic perturbation at a time. The spatial average of the positive values of frontogenesis at $850 \mathrm{hPa}$ over the whole region (DFG+) is used to represent the strength of the perturbation. ECMWF ERA-40 reanalysis data set is used to calculate DFG+ at six hour intervals for 21 seasons (1981-2002). Compositing analysis is carried out for strong (above the 0.75 quantile) and weak (below the 0.25 quantile) events. For strong events the geopotential field at $850 \mathrm{hPa}$ exhibits the North Argentinean Low (NAL), a transient trough and the Low Pressure Tongue East of the Andes (LPT). Upon comparison with the composite field of FGD it can be observed that FGD exhibits a strong maximum over the Argentinean $\mathrm{Col}$ (AC) which separates the NAL and the trough. These features are absent in the weak frontogenesis composite, which exhibits a stronger South Pacific Subtropical High close to the continent. At $250 \mathrm{hPa}$ the strong FGD composite exhibits a trough over the Andes with a wind speed maximum to its east. Both of these features are associated with the deepening of the NAL in the literature.
\end{abstract}

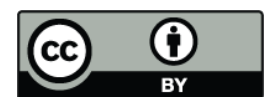

Correspondence to: J. M. Arraut (josefina.arraut@cptec.inpe.br)
These are not present in the weak FGD composites. Strong events show an intense quasi meridional corridor of water vapor transport from the Amazon to the subtropics that encounters westerly flow in the neighborhood of the AC. This is absent in weak events. A preliminary analysis of precipitation is carried out using the GPCP daily data set. An intense precipitation nucleus appears slightly northeast of the $\mathrm{AC}$, with maximum intensity in the day that follows the strong events. Weak events exhibit a drying of the subtropics instead, between one and three days after the events. Higher precipitation over the oceanic South Atlantic Convergence Zone can be also observed. Analogous composites were constructed for the presence and absence of both the AC and the LPT, showing similar characteristics to the strong and weak FGD event composites respectively, but with lower intensities. This shows that by selecting strong FGD events, intense NAL and LPT events are also singled out.

\section{Introduction}

South America east of the Andes is a place of frequent interchange of air masses between the tropics and the midlatitudes, deeply affecting its weather and climate. The Andes Cordillera plays a central role in promoting this interchange in more than one way. In the first place, it efficiently blocks the low level zonal flow. During summer, when the easterly trade winds entering the continent from both hemispheres have a northerly component, this blocking effect channels them southwards, promoting transport of tropical air into higher latitudes (Virji, 1981; Kleeman, 1989; Marengo et al., 2002, 2004). During winter the North

Published by Copernicus Publications on behalf of the European Geosciences Union. 
Atlantic High penetrates the continent and a similar channelling can be observed with easterly winds from its northern branch. Incursions of midlatitude air into the subtropics and tropics, termed cold air incursions, happen all year round (Parmenter, 1976; Kousky, 1979; Marengo et al., 1997). Garreaud and Wallace (1998) and Garreaud (2000) explained the mechanism: the Andes dam the easterly flow north of transient highs penetrating the continent from the Pacific. This leads to the formation of a high pressure dome east of the mountains which forces the air northwards with the Cordillera acting as a western border that compensates the Coriolis force.

A second and indirect way in which the Andes affect wind flow over the continent is through the Northwestern Argentinean Low (NAL). This low, which forms close to the mountains, increases the westward component of the pressure gradient force over the continent and promotes geostrophic southward flow to its east. During summer it forms mostly due to strong surface heating but is particularly intense when a westerly jet is present in high levels over the Cordillera. Many authors have attributed this to heating through the Foehn effect, locally called the Zonda winds. During winter, when surface heating is less intense, this seems to be the main formation mechanism (Lichtenstein, 1980; Seluchi et al., 2003; Ferreira, 2008).

During summer, tropical air masses that migrate southwards over South America are very moist because they form over the warm tropical Atlantic and flow over Amazonia, whereas midlatitude air is both colder and drier. In this context strong frontogenesis in equivalent potential temperature would mark particularly intense encounters of air masses. Such an environment could promote the development of strong convection.

It will be shown that subtropical South America east of the Andes exhibits strong climatological frontogenesis in equivalent potential temperature, which is mainly due to deformation of the wind field. Compositing analysis will be used to investigate the large scale conditions under which this frontogenesis occurs and evaluate its effect over rainfall.

As will be seen, in situations of high frontogenesis the geopotential field exhibits the NAL, a transient trough to its south and an elongated trough reaching from $40^{\circ} \mathrm{S}$ to the deep tropics that envelops both. This elongated trough is termed the Low Pressure Tongue east of the Andes (Arraut, 2007), it allows for the formation of an intense moisture corridor from the deep tropics of the continent into its subtropics and midlatitudes. Frontogenesis by deformation is maximum over the col separating the NAL from the transient trough, which is here called the Argentinean Col. The idea of frontogenesis being favoured by the deformation of the wind field around a col was first put forward by Petterssen (1956). It will be seen that, while the NAL and Low Pressure Tongue structure promote the transport of tropical air to the subtropics and into the midlatitudes, the wind field in the neighborhood of the Argentinean Col favours the encounter of the tropical air mass with the colder and drier extra-tropical westerlies. Intense rainfall is shown to ensue with a 1-day delay.

Another compositing analysis is carried out to investigate the large scale conditions associated with the presence and absence of the Argentinean Col (AC) inside the studied region and the Low Pressure Tongue east of the Andes (LPT). To achieve this it was necessary to use an algorithm for automatic detection of these features, which is described in Barbosa and Arraut (2009).

\section{Data and methods}

Temperature, humidity and wind fields are taken from the European Centre for Medium Range Weather Forecasts (ECMWF) 40 years Reanalysis (ERA-40). These data are available at six hour intervals and twenty one December to March seasons are studied, from December 1981 to March 2002. In total 10184 time instants were analyzed, each being seen as an event. Frontal incursions generally happen over a few days so that many of our events are not independent. However this is not a problem since this assumption is not necessary for our conclusions.

Rainfall is taken from the Global Precipitation Climatology Project (GPCP) One-Degree Daily Precipitation Data Set (Huffman et al., 2001). This dataset is available on a daily basis from October 1996 onwards and for this reason the compositing analysis of the precipitation field is based only on seven seasons. Moreover, the rainfall rate of a day is repeated in the four ERA40 time instants. Equivalent potential temperature, $\theta_{e}$, is calculated according to Bolton (1980). Frontogenesis in $\theta_{e}, F G$, is calculated using the decomposition suggested by Ninomiya (1984):

$$
F G=\frac{d\left|\nabla \theta_{e}\right|}{d t}=F G_{1}+F G_{2}+F G_{3}+F G_{4}
$$

where

$$
\begin{aligned}
F G_{1}= & \frac{1}{\left|\nabla \boldsymbol{\theta}_{\boldsymbol{e}}\right|}\left[\left(\boldsymbol{\nabla} \boldsymbol{\theta}_{\boldsymbol{e}} \cdot \nabla\right) \frac{d \theta_{e}}{d t}\right] \\
F G_{2}= & -\frac{1}{2} \cdot \frac{1}{\left|\boldsymbol{\nabla} \boldsymbol{\theta}_{\boldsymbol{e}}\right|} \cdot\left(\boldsymbol{\nabla} \boldsymbol{\theta}_{\boldsymbol{e}}\right)^{2} D \\
F G_{3}= & -\frac{1}{2\left|\nabla \boldsymbol{\theta}_{\boldsymbol{e}}\right|}\left[\left\{\left(\frac{\partial \theta_{e}}{\partial x}\right)^{2}-\left(\frac{\partial \theta_{e}}{\partial y}\right)^{2}\right\} A\right. \\
& \left.+2 \frac{\partial \theta_{e}}{\partial x} \frac{\partial \theta_{e}}{\partial y} B\right] \\
F G_{4}= & -\frac{1}{\left|\nabla \boldsymbol{\theta}_{\boldsymbol{e}}\right|} \frac{\partial \theta_{e}}{\partial p}\left(\frac{\partial \theta_{e}}{\partial x} \frac{\partial w}{\partial x}+\frac{\partial \theta_{e}}{\partial y} \frac{\partial w}{\partial y}\right)
\end{aligned}
$$

$D$ is the divergence while $A=\partial u / \partial x-\partial v / \partial y$ and $B=\partial v / \partial x+\partial u / \partial y$ are deformations. $F G_{1}$ is the frontogenesis due to diabatic changes of $\theta_{e} . F G_{2}$ and $F G_{3}$ are associated with the large scale horizontal flow. The first 
represents the effect of divergence and the latter that of deformation. $F G_{4}$ accounts for vertical advection of $\theta_{e}$.

As the next section will show, frontogenesis exhibits an intense maximum over the continent and the deformation term is by far the most important one. This is in accordance with Ninomiya (1984); Kodama (1992), who found $F G_{3}$ to be the main contributor to frontogenesis in the troposphere. The region of strong frontogenesis over the continent is mostly from $-42.5^{\circ} \mathrm{S}$ to $-30^{\circ} \mathrm{S}$ and $-70^{\circ} \mathrm{W}$ to $-62.5^{\circ} \mathrm{W}$, which is small enough to contain only one synoptic disturbance at any given time. For this reason the spatial average of frontogenesis over the region affords a simple measure of the intensity of the disturbance. Fronts are quite smaller in width than the latitudinal length of our region, so the spatial average on its own does not adequately narrow down their position. This could lead to "fuzzy" composites. However the frontogenesis composite produced is sharp, which evidences a very small variation of latitudinal position for fronts crossing this region. This we attribute to their path being constrained by the geometry of the local pressure field (Arraut, 2007). This issue will be further dealt with in the Sect. 4 .

There is one other matter to be considered in the averaging procedure. Frontogenetic disturbances can be followed by frontolysis which would mask the intensity of the event. To avoid this all negative values are substituted by zero when the mean is taken and the result is called DFG+. This is better than averaging over the area of positive frontogenesis because strong disturbances only partially contained in the studied region are less likely to become part of the high frontogenesis composites. This avoids the inclusion of different stages of the displacement of a front in the composite, which could cause undesired smoothing of important features.

The time series of spatially averaged frontogenesis is analysed and compositing analysis is performed for values above the 0.75 quantile and below the 0.25 quantile. That is to say, of all times analysed the upper quarter according to frontogenesis intensity is considered as well as the lower quarter.

\section{Climatological frontogenesis}

Figure 1 shows the climatology of total frontogenesis as well as that of each separate term. For total frontogenesis a strong maximum is present close to the Andes between $30^{\circ} \mathrm{S}$ and $40^{\circ} \mathrm{S}$ and a diagonal band stretching southeastwardly into the ocean can be seen. The deformation term gives the most important contribution. It is the most intense, with a maximum east of the Andes around $37^{\circ} \mathrm{S}$, and also accounts for the diagonal structure reaching the coastal Atlantic. For this reason only the deformation term is considered from now on and it will simply be called frontogenesis.
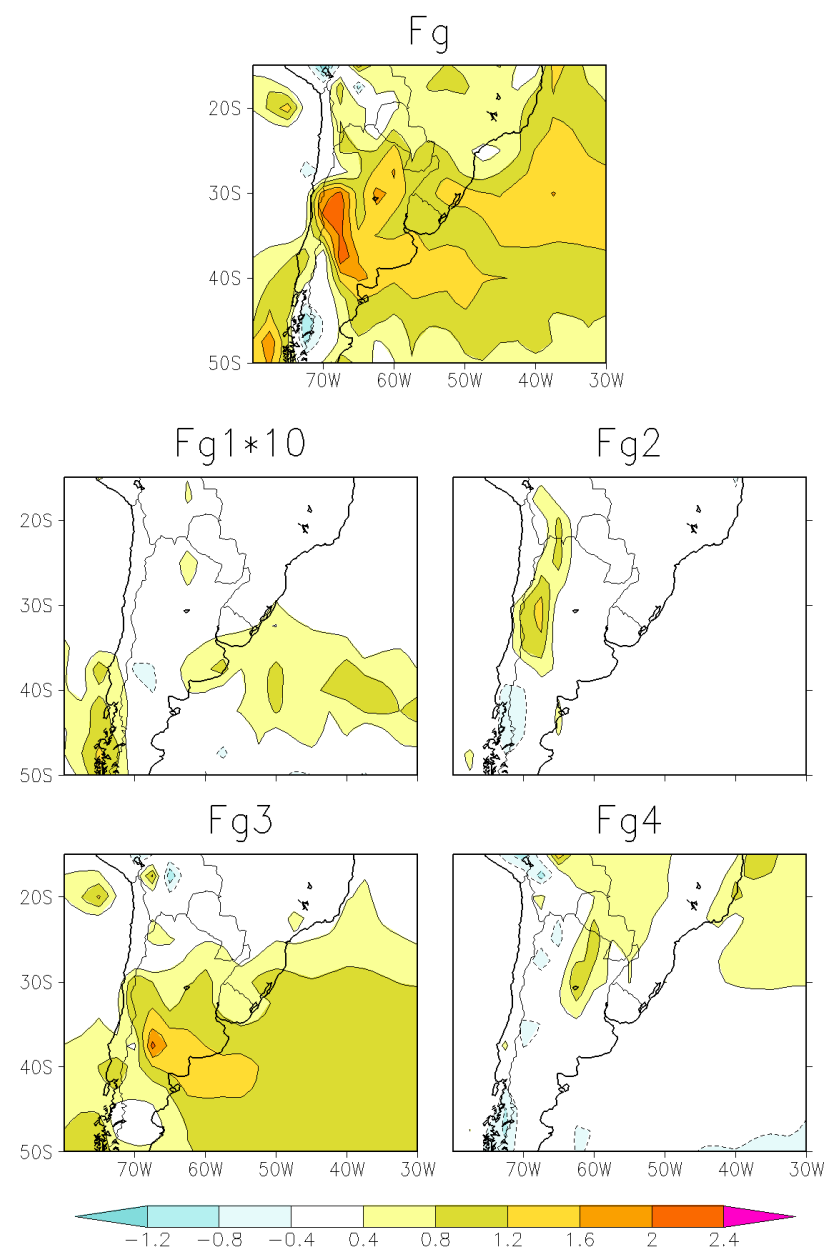

Fig. 1. Climatology of frontogenesis in $\theta_{e}(\mathrm{~K} / 100 \mathrm{~km} /$ day $)$ at $850 \mathrm{hPa}$. Total frontogenesis $F g$ is the sum of the four terms $F G_{1}$, $F G_{2}, F G_{3}$ and $F G_{4}$, calculated following Ninomiya (1984).

\section{Compositing analysis}

\subsection{Frontogenesis composites}

The top panels of Fig. 2 show geopotential and frontogenesis, both at $850 \mathrm{hPa}$ for high (left) and low (right) frontogenesis situations.

\subsubsection{High frontogenesis}

A sharp maximum can be seen over the continent, slightly north of $40^{\circ} \mathrm{S}$. A much weaker diagonal band stretches southeastwardly into the Atlantic. This shows that fronts passing inside the studied region have positions which, for this data resolution, are almost coincident.

The geopotential field shows the Low Pressure Tongue east of the Andes, the NAL as well as a transient trough to its south. All of these features are sharp and similar to what can be seen in individual events (not shown). The location 

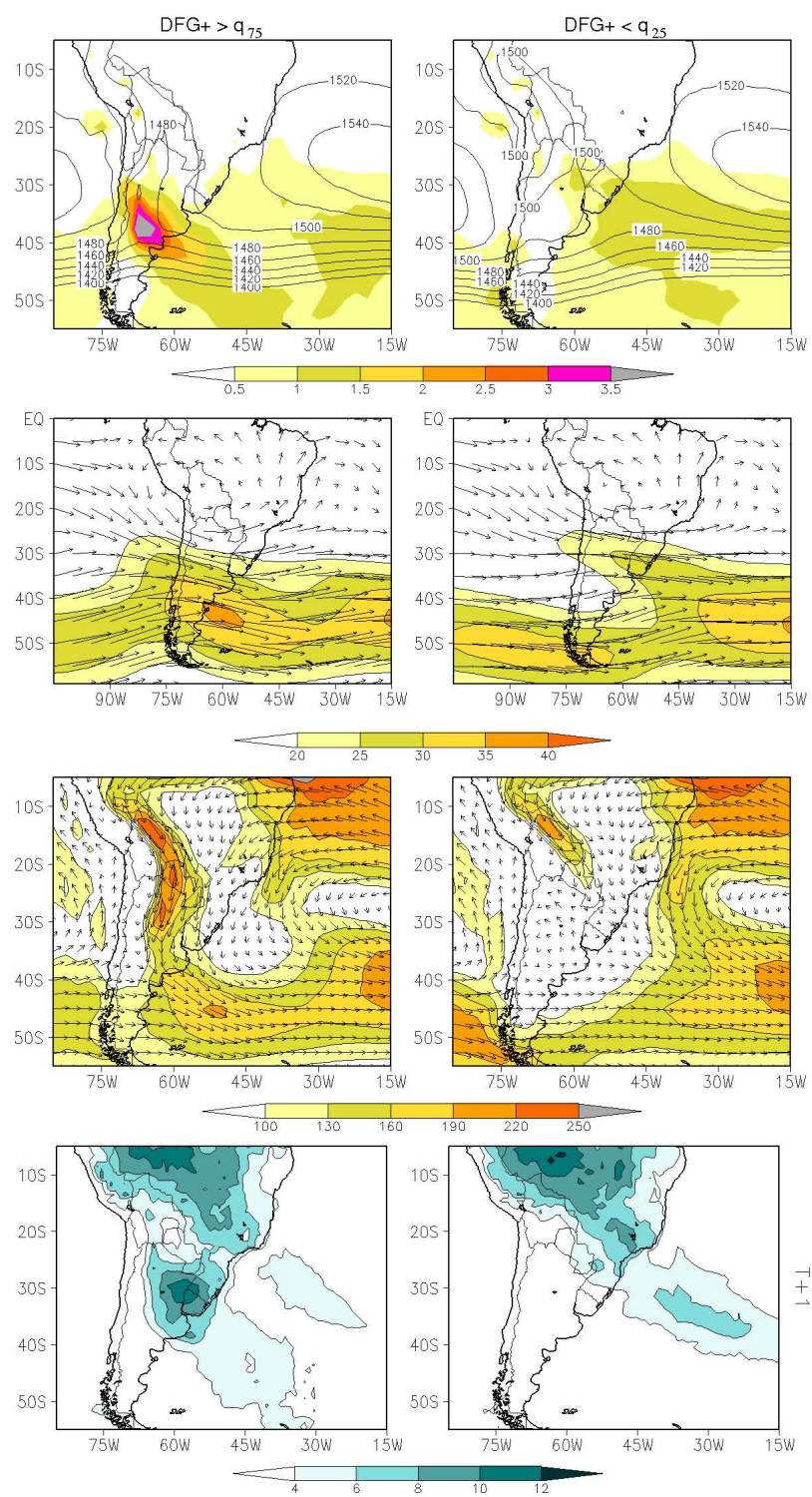

Fig. 2. Composites for cases with $\mathrm{DFG}+>q_{0.75}$ (left) and $\mathrm{DFG}+<q_{0.25}$ (right) are shown. From top to bottom, the panels show geopotential height $(\mathrm{m})$ and $F G_{3}(\mathrm{~K} / 100 \mathrm{~km} /$ day $)$ at $850 \mathrm{hPa}$, wind vectors and its magnitude $(\mathrm{m} / \mathrm{s})$ at $250 \mathrm{hPa}$, vertically integrated humidity transport and its magnitude $(\mathrm{kg} / \mathrm{m} / \mathrm{s})$, and precipitation (mm/day) with 1-day lag.

of the Argentinean $\mathrm{Col}$ is coincident with that of strongest frontogenesis.

Composites of wind vectors and wind speed, both at $250 \mathrm{hPa}$ are shown on the second row of panels of Fig. 2. For high frontogenesis there is a trough straddling the Andes with a maximum of wind speed to its east. These features are compatible with the initial phase of a frontal incursion. They are similar to those reported during NAL events and the presence and position of the wind speed maximum is such as would cause the Zonda wind (Lichtenstein, 1980; Seluchi et al., 2003; Ferreira, 2008).
The third row of panels of Fig. 2 show vectors of vertically integrated moisture transport as well as its intensity. High frontogenesis situations exhibit an intense moisture transport corridor close to the eastern Andes from the deep tropics all the way to the midlatitudes. Comparing with the geopotential field it can be seen that this transport takes place on the eastern side of the Low Pressure Tongue and close to the Argentinean Col it diminishes, increasing again to its south. In the neighborhood of the Col this flow encounters the extratropical westerlies accounting for the, previously discussed, intense frontogenesis. While the NAL and Low Pressure Tongue promote the southward transport of the tropical air mass, the geometry of the wind field in the neighborhood of the Col favors a violent encounter with the colder and drier extra-tropical air.

Composites of rainfall with one day lag are shown in the bottom panels of Fig. 2. For high frontogenesis a strong, vaguely circular, rainfall pattern with intensity reaching above $12 \mathrm{~mm} /$ day can be seen over the triple frontier of Brazil, Uruguay and Argentina. This is immersed in a much weaker diagonal band extending into the South Atlantic. It is located slightly to the northeast of the $\mathrm{AC}$, where moisture transport slows down, likely due to convergence.

\subsubsection{Low frontogenesis}

None of the features observed in the high frontogenesis composites are present in those for low frontogenesis. In fact, high level winds show a weak ridge straddling the Andes. The direction of vertically integrated moisture flow reflects that of low level winds and is from the south in the subtropics. Low level geopotential also shows a weak ridge. The 1-day lagged rainfall shows a drying of the continental subtropics and an enhancement of rainfall in a diagonal band over the ocean, to the northeast. These are compatible with the situation following a frontal incursion.

\subsection{Argentinean Col composites}

Figure 3 presents composites analogous to the one described above, but built for the presence and absence of the Argentinean Col inside the study region and the Low Pressure Tongue east of the Andes. For simplicity these shall be called $\mathrm{AC}$ and no-AC composites. AC composites contain $42 \%$ of all events while no-AC composites contain the remaining $58 \%$.

It is important to note that the Argentinean Col is a geometrical necessity whenever the NAL is formed. This can be easily seen by considering the geostrophic wind field; a col is necessary to separate the easterlies south of the NAL from the extra-tropical westerlies. In fact the algorithm for detection of the Col begins by searching for the NAL . In these composites it is verified if the Argentinean Col lies within the studied region, as well as if its separatrices form a self connection containing the NAL. Occurrences of the Argentinean 
Col are in fact highly concentrated in the studied region (see Arraut, 2007 and Arraut and Barbosa, 2009).

It is interesting to note that AC composites are all qualitatively similar to high frontogenesis composites, although showing lower intensity. In particular we point out that the geopotential and frontogenesis composites show a maximum of frontogenesis over the Argentinean Col with a diagonal band protruding southeastwardly into the Atlantic. Frontogenesis is weaker than in the high frontogenesis composite which contains the strongest $25 \%$, while $42 \%$ of events are included in this case. Interestingly however, the NAL and Low Pressure Tongue are also weaker, as is the meridional moisture transport on their eastern flanks. This shows that by selecting high frontogenesis events, strong cases of the Low Pressure Tongue were also selected.

\section{Conclusions}

It was shown that the South American subtropics exhibit high frontogenesis in equivalent potential temperature during summer. Deformation of the wind field is the most important contributor.

The synoptic situation associated with high frontogenesis includes a high level trough straddling the Andes with a maximum of wind speed to its east. The NAL and Low pressure Tongue are formed over the continent, on their eastern flanks intense moisture flow from the tropics into the subtropics and midlatitudes takes place. Frontogenesis exhibits an intense and sharp maximum over the continent, its position coinciding with that of the Argentinean Col.

It is relevant to observe that the simultaneous presence of the high level wind maximum over the continent and the NAL in the low levels is in agreement with the findings of previous authors regarding the contribution of the Zonda wind to the formation of the NAL.

It is concluded that:

1. High frontogenesis over subtropical South America occurs when frontal incursions foster the NAL and Low Pressure Tongue formation.

2. These structures promote the transport of tropical air into the subtropics and midlatitudes, thus enhancing frontogenesis.

3. The geometry of the wind field in the neighborhood of the Argentinean Col is such that it promotes the "violent" encounter of the tropical air with the extra-tropical westerlies, accounting for the maximum of frontogenesis.

4. From this encounter of air masses strong precipitation ensues, with maximum intensity delayed one day.
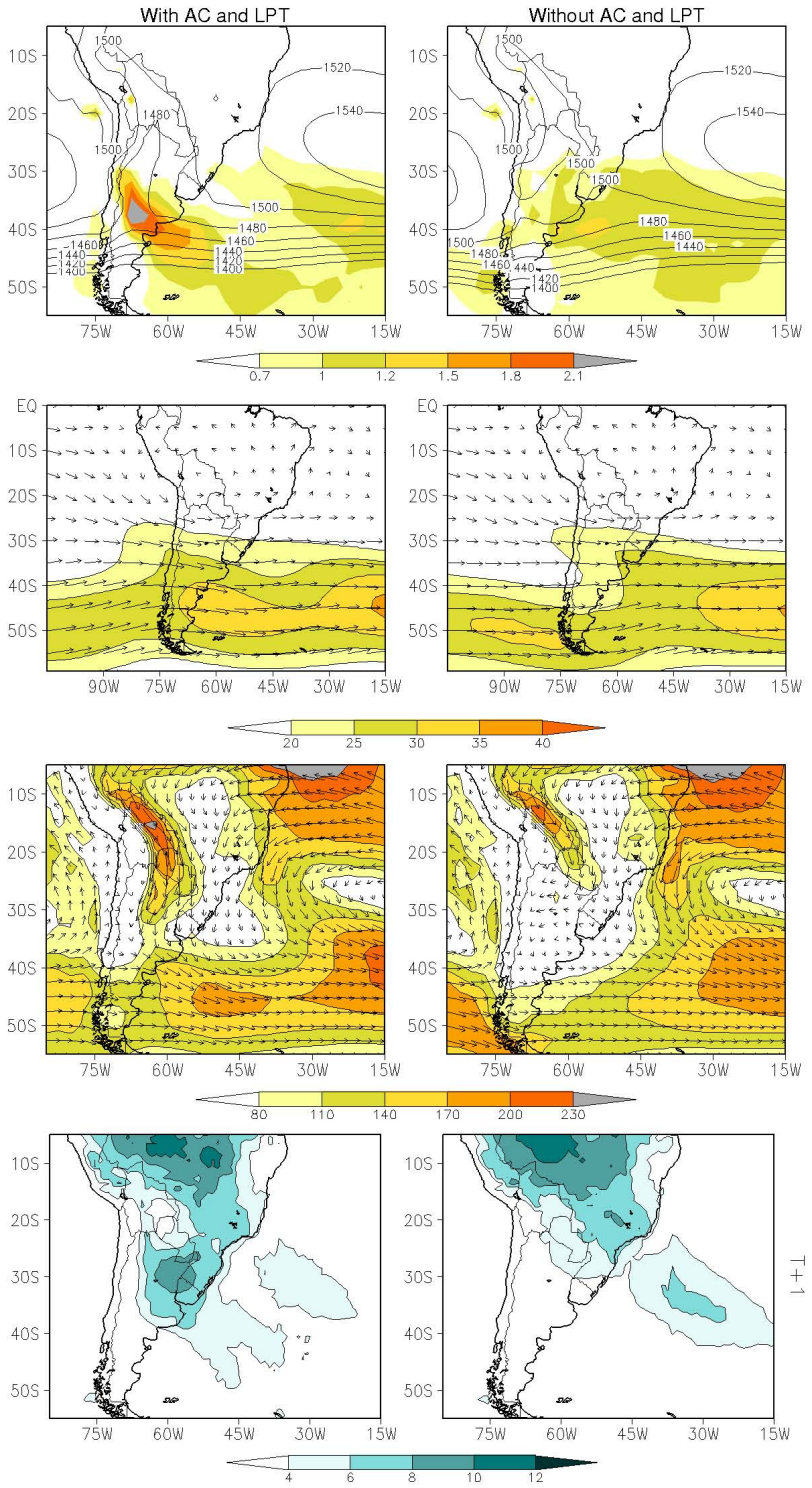

Fig. 3. Composites for cases with (left) and without (right) AC and LPT inside the selected region. From top to bottom, the panels show geopotential height $(\mathrm{m})$ and $F G_{3}(\mathrm{~K} / 100 \mathrm{~km} /$ day $)$ at $850 \mathrm{hPa}$, wind vectors and its magnitude $(\mathrm{m} / \mathrm{s})$ at $250 \mathrm{hPa}$, vertically integrated humidity transport and its magnitude $(\mathrm{kg} / \mathrm{m} / \mathrm{s})$, and precipitation (mm/day) with 1-day lag.

The rainfall pattern is compatible with that of Meso-scale Convective Complexes and the question of whether the $\mathrm{Ar}$ gentinean $\mathrm{Col}$ promotes the formation of MCCs merits investigation.

All of the above described features are more intense in the high frontogenesis composites than in the $\mathrm{AC}$ composites, even the AC and LPT themselves. While the high frontogenesis composites include $25 \%$ of all events the AC composites include $42 \%$. This shows that by selecting higher frontogenesis strong NAL and LPT cases are indirectly selected. 
Acknowledgements. The first author thanks J. L. Arraut for helpfull discussions. This research was partially financed by "Coordenadoria de Aperfeiçoamento de Pessoal do Ensino Superior (CAPES)". ECMWF ERA40 data used in this study have been obtained from the ECMWF data server.

Edited by: R. Garraud

Reviewed by: two anonymous referees

\section{References}

Arraut, J. M.: Fronts and frontogenesis during summer: geometrical and dynamical aspects and the influence over rainfall on the South American subtropics, Ph.D. thesis, Centro de Previsão de Tempo e Estudos Climáticos - INPE, Rodovia Presidente Dutra Km 40 Cachoeira Paulista, São Paulo, Brasil, online available at: http://urlib.net/sid.inpe.br/mtc-m17@80/2007/12.19.10. 53, 2007 (In Portuguese).

Arraut, J. M. and Barbosa, H. M. J.: Large Scale Features Associated with Strong Frontogenesis in Equivalent Potential Temperature in the South American Subtropics East of the Andes, Adv. Geosci., this special volume, 2009.

Barbosa, H. M. J. and Arraut, J. M.: A quantitative evaluation of the role of the Argentinean $\mathrm{Col}$ and the Low Pressure Tongue East of the Andes for frontogenesis in the South American subtropics, Adv. Geosci., this special volume, 2009.

Bolton, D.: The Computation of Equivalent Potential Temperature, Mon. Weather Rev., 108, 1046-1053, 1980.

Ferreira, L.: Causes and Variability of the Northwestern Argentinean Low and Impacts Over Local Circulation Patterns (in Spanish), Ph.D. thesis, Universidade de Buenos Aires, 2008.

Garreaud, R. D.: Cold Air Incursions Over Subtropical South America: Mean Structure and Dynamics, Mon. Weather Rev., 128, 2544-2559, 2000.

Garreaud, R. D. and Wallace, J. M.: Summertime Incursions of Midlatitude Air into Subtropical and Tropical South America, Mon. Weather Rev., 126, 2713-2733, 1998.

Huffman, G. J., Adler, R., Morrissey, M., Curtis, S., Joyce, R., McGavock, B., and Susskind, J.: Global precipitation at one-degree daily resolution from multi-satellite observations, J. Hydrometeorol., 2, 36-50, 2001.
Kleeman, R.: A Modeling Study of the Effect of the Andes on the Summertime Circulation of Tropical South America, J. Atmos. Sci., 44, 3344-3362, 1989.

Kodama, Y.-M.: Large-Scale Common Features of Subtropical Precipitation Zones (the Baiu Frontal Zone, the SPCZ and the SACZ) Part I: Characteristics of Subtropical Frontal Zones, J. Meteorol. Soc. Jpn, 70, 813-835, 1992.

Kousky, V. E.: Frontal influences on northeast Brazil, Mon. Weather Rev., 107, 1142-1153, 1979.

Lichtenstein, E. R.: La depresion del noroeste argentino (The northwestern Argentinian low), Ph.D. thesis, Departamento de Ciencias de la Atmosfera, Ciudad Universitaria (1428) Buenos Aires, Argentina, 1980.

Marengo, J., Douglas, M., and Silva Dias, P. L.: The South American Low Level Jet East Of the Andes During the 1999 LBATRMM and LBA-WET AMC Campaing, J. Geophys. Res., 107, 47-1-47-11, 2002

Marengo, J., Soares, W., Saulo, C., and Nicolini, M.: Climatology of the Low Level Jet East of the Andes as derived from the NCEP-NCAR reanalysis: characteristics and temporal variability, J. Climate, 17, 2261-2280, 2004.

Marengo, J., Cornejo, A., and Satyamurty, P. et al.: Cold Surges in Tropical and Extratropical South America: the Strong Event in June 1994, Mon. Weather Rev., 125, 2759-2786, 1997.

Ninomiya, K.: Characteristics of Baiu Front as a predominant subtropical front in the summer northern hemisphere, J. Meteorol. Soc. Jpn, 62, 880-894, 1984.

Parmenter, F. C.: A southern hemisphere cold front passage at the equator, B. Am. Meteorol. Soc., 57, 1435-1440, 1976.

Petterssen, S.: Weather analysis and forecasting, McGraw-Hill, New York, 2nd edn., 1956.

Seluchi, M. E., Saulo, C., Nicolini, M., and Satyamurty, P.: The Northwestern Argentinean Low: A study of two typical events, Mon. Weather Rev., 132, 2361-2378, 2003.

Virji, H.: A preliminary study of summertime tropospheric circulation patterns over South America estimated from cloud winds, Mon. Weather Rev., 109, 599-610, 1981. 